\title{
Determination of free fatty acids in crude palm oil, bleached palm oil and bleached deacidified palm oil by fourier transform infrared spectroscopy.
}

\begin{abstract}
A rapid method for quantitative determination of free fatty acids from crude palm oil to bleached palm oil (BPO) and then distilled BPO and refluxed BPO by Fourier transform infrared (FTIR) transmission spectroscopy is described. A partial least square (PLS) model was calibrated to predict the FFA content of palm oil samples based on the spectral range of $1,729.89-1,694.48 / \mathrm{cm}$. Multivariate calibration step was carried out by comparing the FFA values predicted by PLS model to the values obtained from the official American Oil Chemists' Society method. The resulting PLS calibrations were linear and the root mean standard error of cross-validation was 0.063 with a correlation coefficient (R2) of 0.9898 . The results indicated that FTIR spectroscopy is an efficient, rapid and accurate method for determining the FFA content in palm oil.
\end{abstract}

Item Type: Article

Keyword: Free fatty acids; Palm oil; Infrared spectroscopy. 